\title{
The Advantages of L2 Translation in The Cat in the Hat: A Closer Look at Translation Directionality ${ }^{1}$
}

\author{
Meghan Posey ${ }^{2}$
}

Campus Crusade, Costa Rica

\section{RESUMEN}

Es un estudio que plantea un aspecto traductológico específico: la traducción a la segunda lengua de quien traduce. A partir del análisis de una traducción al español de The Cat in the Hat, de Dr. Seuss, obra de literatura infantil, se señalan ciertas ventajas metodológicas que tienen que ver con la competencia cultural, la comprensión apropiada del texto original y un acercamiento lingüístico más consciente de la lengua terminal.

\section{Abstract}

This study focuses on translation directionality; in particular, translating to one's second language. Based on a Spanish translation of the children's book The Cat in the Hat, by Dr. Seuss, this article discusses certain methodological advantages of translating to one's second language: cultural competency, an appropriate understanding of the source text, and an enhanced linguistic awareness of the target language.

Palabras clave: metodología de la traducción, direccionalidad traductológica, traducción inversa, literatura infantil

Keywords: translation methodology, directionality, inverse translation, children's literature

Received: July 30, 2008; accepted: August 20, 2009.

E-mail: posmeg@gmail.com 
Translation studies have tended to neglect the study of translation directionality, and even when they do dedicate some time to the matter, they tend to focus on the problems of L2 translation. Translation into the mother tongue is often the preferred direction of translation, but since translators rarely work in ideal conditions, what happens when they are faced with a task that requires them to translate away from their native language? Why is it that translation into one's second language $(\mathrm{L} 2)^{3}$ is viewed as a substandard version of some ideal target? The field of translation does not have much to say about inverse translation; however, there are seemingly countless books that claim that translating into one's mother tongue is the only viable option for the translator. One such purist is Newmark, who believes that "Translating into your language of habitual use is the only way you can translate naturally and accurately and with maximum effectiveness."4

This article begs to differ with Newmark, and proposes that translation into one's non-native language has its advantages and its end product can be achieved with equal competency. Using the children's book The Cat in the Hat by Dr. Seuss and its translation into Spanish by Carlos Rivera, ${ }^{5}$ this analysis seeks to offer an alternative translation that has been created by a non-native Spanish speaker. As McAlister suggests, a non-native speaker can translate a text competently by "transmitting the intended message in a language which is clear and sufficiently correct."

3 According to convention, we use the following abbreviations throughout the text: ST (source text), TT (target text), SL (source language), TL (target language), SC (source culture), TC (target culture), $\mathrm{Ll}$ (first language, generally the mother tongue), and L2 (second language).

4 Peter Newmark, A Textbook of Translation (London: Prentice-Hall International, 1988) 3.

5 Dr. Seuss, The Cat in the Hat (New York: Random House, 1957); Carlos Rivera (trans.), The Cat in the Hat: In English and Spanish by Dr. Seuss (New York: Random House, 1967). Page numbers given in parentheses ref er to these editions.

6 Mona Baker and Kirsten Malmkjaer, Routledge Encyclopedia of Translation Studies (New York: Routledge, 1998) 66. 
The attitudes towards the directionality of translation and its acceptance are reflected in the specific terminology used to describe each type; translation into the mother tongue, a vision of warmth and acceptance compared with the term "inverse translation" which evokes a feeling of "going in the wrong direction." This attitude could be justified by a close encounter with a third kind, or in our case, with a second kind (L2 translation) of texts that have been translated poorly, despite the fact that there are probably just as many nonsense translations to be found into one's first language ( $\mathrm{Ll}$ translation). For the purposes of this paper, we will use the term "L2 translation," to include "le thème," "inverse," "reverse," and "service" translation and the term "L1 translation," to include "direct," "mother tongue," "native language," and "language of habitual use" translation. ${ }^{8}$

Translation directionality has not always been such a polemic issue; for example, in the Christian era most of the translations in Europe were into Latin, the established official language, used in religion and learning. The superiority of $\mathrm{Ll}$ translation can be traced to the rise of the nation-states and the Reformation, with Martin Luther most likely being the first to adamantly proclaim that the best translations were always into the mother tongue. From that moment in history ( $16^{\text {th }}$ century) L 2 translation began to be viewed "only as a pedagogical exercise by translation theorists." 9 Fast forward a couple of centuries to the present where L2 translation, although gaining ground within our multilinguistic society, is still viewed as second best. According to Campbell, who might be the exception to his own revelation, translation studies have "virtually ignored the reality of translation into the second language."10 Perhaps this is due to a misconstrued conception of a translator who works in ideal conditions.

Nataša Pavlović, Directionality in Translation and Interpreting Practice. Report on a Questionnaire Survey in Croatia, <http://isg.urv.es/library/papers/PavlovicDirectionality.pdf>, retrieved 23 Oct. 2007.

8 Terms used by Nataša Pavlović.

9 Baker and Malmkjaer, 64.

10 Stuart Campbell, Translation into the Second Language (New York: Addison Wesley Longman, 1998) 20. 
The reality is quite the contrary, however, for there are not always enough translators in the right place at the right time with the right skills to translate into their native tongue. A translator's decision to translate into his/her L2, could be based on a variety of factors, such as a specific text type or a deadline that must be met. For many clients, the luxury of asking the translators what directionality they will be employing is non-existent. "If the source language and the target language are in close contact (geographical, commercial and cultural proximity) there will be more translators available, and it will be easier to find one to translate into the mother tongue." When such proximity does not exist, translators must resort to the tools that they already have to complete the task. "For example, in Spain, most translations from Chinese, Japanese and Arabic into Spanish are inverse translations."

For this and many other reasons, translation students should be trained to work in their L2 as well as their L1. Graduate programs should be equipping their students with strategies and techniques that will help them master the syntax and semantics of the L2 language. It is doubtful that anyone would refute that L2 translation is more challenging, but just like writers desiring to improve their abilities, translators may improve their L2 translation skills. According to Campbell, "the ability to translate into a second language develops in a systematic way." 12 Among L2 translators three levels of competence have been proposed by Campbell, each with their own characteristics: substandard, pretextual, and textual.

\footnotetext{
11 Baker and Malmkjaer, 65.

12 Campbell, 22.
} 


\section{Defining characteristics of the three levels of competence ${ }^{13}$}

\begin{tabular}{|l|l|}
\hline $\begin{array}{l}\text { Level of } \\
\text { Competence }\end{array}$ & Characteristics of text at this level \\
\hline Substandard & $\begin{array}{l}\text { Spelling is very inaccurate; source text is not fully } \\
\text { translated and target text is short; function words } \\
\text { are of ten omitted so that text contains high } \\
\text { proportion of content words, especially nouns; } \\
\text { translation is rather indirect because of efforts to } \\
\text { cope with poor target language repertoire }\end{array}$ \\
\hline Pretextual & $\begin{array}{l}\text { Spelling is accurate; source text is fully translated; } \\
\text { text is long and strung out because of use of } \\
\text { function words rather than lexicalizations; } \\
\text { vocabulary is not varied; translation is structurally } \\
\text { very close to the source text; style is more 'verby'. }\end{array}$ \\
\hline Textual & $\begin{array}{l}\text { Spelling is accurate; source text is fully translated; } \\
\text { text is short and syntactically dense through the } \\
\text { use of lexicalizations; style is more nominal, and } \\
\text { words are longer and more varied; the text is } \\
\text { structurally more distant form the original because } \\
\text { of grammatical shifts and indirect translation of } \\
\text { source text words. }\end{array}$ \\
\hline
\end{tabular}

With this is mind, when we refer here to the L2 translator, we are referring to a translator in Campbell's third level of competency, one who is textually competent. Rather than concentrate on the negative aspects of L2 translation, which so many other articles have covered already, this analysis highlights the positive aspects of L2 translation. It suggests that the L2 translator has at least three advantages over the Ll translator: 1. higher cultural competency; 2.

$\overline{13 \text { Campbell, } 48 .}$ 
less likelihood of misunderstanding the ST; and 3. greater care with the use of the target language. Before discussing each advantage in depth, we must first take a look at our texts.

To illustrate these advantages, we have chosen a classical American children's book as our source text, entitled The Cat in the Hat written by Theodor Seuss Geisel, otherwise known as Dr. Seuss. The text was later translated into Spanish by Carlos Rivera and given the title El gato ensombrerado. Yet, it was quickly apparent that the literal translation provided by Carlos Rivera was lacking in many ways. Examples of this can be observed in the many unsatisfactory remarks included in the customers' reviews on amazon.com. A reader described El gato ensombrerado as "clunky, non-rhyming, and completely devoid of the charm so characteristic of Dr. Seuss's works," while another rhetorically added, "What good is Dr. Seuss if it doesn't rhyme?" 14 This awakes an inner desire to produce a high quality L2 translation.

\section{The L2 translator possesses higher cultural competency}

Instead of translating the The Cat in the Hat literally as Rivera did, an L2 translator would most likely understand the importance of preserving the musicality that defines Dr. Seuss as an American icon. The first page in The Cat in the Hat, reads:

The sun did not shine.

It was too wet to play.

So we sat in the house

All that cold, cold, wet day. (1)

Rivera's literal translation makes no creative attempt to maintain Dr. Seuss' anapestic diameter ${ }^{15}$ :

14 Customer Reviews, 10 Oct. 2007, <http://www.amazon.ca/Cat-Hat-English-Spanish/dp/ 0394816269>.

15 An anapest is composed of two unstressed syllables followed by a stressed syllable; see Philip Nel, The Annotated Cat: Under the Hats of Seuss and His Cats (New York: Random House, 2007) 30. 
El sol no brillaba.

Estaba demasiado mojado para jugar.

Así es que nos sentamos adentro de la casa

Todo aquel frío, frío, día mojado. (3)

Conversely, an American L2 translator would most likely choose to maintain Dr. Seuss' rhythmic style while replacing it with a rhythmic pattern that is familiar to the target culture. To produce a similar feeling within the Spanish speaking target culture, the following translation by an L2 translator implements a type of verse characteristic of Rubén Darío $^{16}$ :

El sol ya no brillaba

porque afuera llovía y llovía.

En la casa pasamos todo aquel día

porque el césped la lluvia mojaba.

If Rivera had read a text such as Translating Cultures, before translating The Cat in the Hat, he might have understood the importance of concentrating on Dr. Seuss' overall intention.

Rather than any search for equivalence...A cultural mediator, whether translator or interpreter, should concentrate on author intention or text function within a context of culture, and concentrate, in particular, on the facilitation of communication between original author and end receiver. ${ }^{17}$

\footnotetext{
16 Rubén Dario is considered one of Latin America's greatest poets, and is known as the Father of Modernism. He was famous for his rhythmic style of ABBA. Homenaje Pennanente a Rubén Dario, <http://www.dariana.com/Dario-poemas.html>, retrieved 10 Oct. 2007.

17 David Katan, Translating Cultures: An Introduction for Translators, Interpreters and Mediators (Manchester, St. Jerome Publishing, 1999) 17.
} 
Instead, Rivera decided to concentrate on the semantic equivalence of each line.

The L2 translator will have a tendency to be more in-tune with the original writer. Dr. Seuss is not as recognized to the same degree in other non-English speaking countries, perhaps due to the "difficulty of translating the nonsensical language and wordplay upon which his works depend." ${ }^{18} \mathrm{He}$ has written and illustrated bestsellers such as Green Eggs and Ham (1960), One Fish Two Fish Red Fish Blue Fish (1960), and How the Grinch Stole Christmas! (1957). ${ }^{19}$ Interestingly enough, Dr. Seuss had a background in advertising which undoubtedly allowed him to captivate the American child with greater ease.

Translators often stress the need for a sense of affinity with the poet they are translating, and love for the poet's work together with some degree of inspiration are important factors usually missing from models and theories of poetry translation. As Octavio Paz suggests, 'neither are sufficient, but both are indispensable.' 20

The Cat in the Hat was written in 1957 in an attempt to get children to read more. He based the book on a 236 simple word list that first graders might possess and included rhyme to help the child pronounce words that might be foreign to them. Take this list of items, for example, that the Cat has been ordered to clean up:

He picked up the cake,

And the rake, and the gown,

And the milk, and the strings,

And the books, and the dish,

And the fan, and the cup,

And the ship, and the fish. (58)

\footnotetext{
18 Nel, 105.

19 Dr. Seuss, all published by Beginner Books (New York: Random House).

20 Baker and Malmkjaer, 175.
} 
This sort of playfulness with language spurs children onward even when they think they do not know the next word, because they can guess what rhymes with it and sound the word out. It encourages children to read not only with adults, but also by themselves. In contrast, the Spanish version is very matter-of-fact:
Recogió el pastel,
Y el rastrillo, y el vestido,
Y la leche, y las cuerdas,
Y los libros, y el plato,
Y el abanico, y la taza,
Y el barco, y el pez. (60)

\section{The L2 translator is less likely to misunderstand the ST}

Another advantage of L2 translation in comparison to L1 translation is a greater comprehension of the ST which can result in a better final translation. Shi Aiwei refers to the importance of comprehension, based on Hatim and Mason's description of the process of translation which is composed of three stages: 1) comprehension of ST; 2) transfer of meaning; and 3 ) assessment of TT. ${ }^{21} \mathrm{Ll}$ translators might be able to express themselves with greater ease in the TL but if they do not understand what is being said than there is a breakdown in communication from the very start.

All of the events in the book take place indoors where Sally and her brother (who is referred to as "I" throughout the whole story) are bored to death because it is raining outside and they cannot go outside to play. Their mother is in town for the day and they have been left at home, when the Cat in the Hat barges into their house and gets into all sorts of mischief. He basically turns the house upside down before

21 Shi Aiwei, "Translatability and Poetic Translation." Translatum Journal 2005, <http:// www.translatum.gr/journal/5/translatability-and-poetic-translation.htm>; retrieved 15 Oct. 2007. 
Sally's brother tells him he must leave. The Cat cleans up his mess and exits only minutes before mother comes home and asks the children what they have been up to. The story ends with an open ended question; "What would YOU do, If your mother asked you?" (61), which allows the readers (first graders) to reflect on their own beliefs about telling the truth. Rivera translated the question using the subjunctive form of the verb hacer, “¿Qué hicieras TU si tu mamá TE preguntara?" (63), taking the whole sentence to a very distant realm of possibility, as if the author really does not care what the reader would do, but is just thinking aloud. Yet, it appears that Dr. Seuss did intend for the question to be answered by the reader; he wanted some introspection to take place at the end of the book. A more appropriate word choice by Rivera might have been "que harías si..." or "qué pasaría si...".

\section{The L2 translator is more conscientious with the TT}

Since the TL has a degree of foreignness, it is not surprising that L2 translators will scrutinize their work more carefully than L1 translators. L2 translators will also probably use tools (such as dictionaries or thesauruses) more frequently than $\mathrm{L} 1$ translators do. It would be interesting to compare how many times $\mathrm{Ll}$ translators check their work over before completing their translation in comparison to L2 translators. However, it might be difficult to determine which variables are being measured because the results could be due to a separate variable such as personality type. Since L 2 translators might not be as comfortable in their second language, it might take them longer to complete the translation, but a difference in speed does not always mean a difference in quality. It could mean quite the contrary, for it could produce an end product where each sentence has been carefully examined before being accepted. There are various punctuation errors in Rivera's translation that might have been caught by an L2 translator on the lookout for common mistakes. One mistake 96 
that was identified was a missing accent mark. "Pues, ¿qué DEBIERAMOS hacer?" where "DEBIÉRAMOs" should have had an accent on the "É". The second mistake involved the following sentence: "No teman este revoltijo! —dijo el Gato Ensombrerado-", in which Rivera or his final editor forgot to place the inverted exclamation mark at the beginning of the sentence, as in: “ $i N o$ teman este revoltijo!”. El gato ensombrerado is almost a word for word translation with a several exceptions. Notice the poetic symmetry of the following words in English:

Bump! Thump! Thump! Bump!

Down the wall in the hall. (40)

Rivera left out the contrasting sounds of "Bump" and "Thump", possibly boring the reader with the repetition of " $i$ Pum!" and translated it as:

¡Pum! ¡Pum! ¡Pum! ¡Pum!

En la pared del pasillo. (42)

A closer rendition might be the addition of the word " Bum!" to provide some contrast:

¡Pum! ¡Bum! ¡Bum! ¡Pum!

Como grillos locos en el pasillo.

It is true that in an attempt to make the poem rhyme in Spanish, some creative liberty had to be taken and now the stanza includes crazy grasshoppers that were not in the original text, "Como grillos locos en el pasillo." But this kind of creative liberty is permissible considering that the book is for children and it is meant to make them laugh. The translation should be more than just the concept of the original, but also the excitement and thrill of the source text. 
Translators should try their best to transfer the specific aesthetic and expressive values of the poem. "The aesthetic function of the work shall emphasize the beauty of the words (diction), figurative language, metaphors, etc., while the expressive functions shall put forward the writer's thought (or process of thought), emotion, etc." 22 The straightforward tone of Rivera does neither. Observe how Rivera has translated the possessive pronouns in the following excerpt:

"So, DO something! Fast!" said the fish.

"Do you hear!

I saw her. Your mother!

Your mother is near! (48)

Here is Rivera's translation:

—Así es que, ¡HAGAN algo! ¡Pronto! — dijo el pez-. ¿Oyen Uds.?

La ví. ¡La mamá de Uds.!

¡La mamá de Uds. está cerca! (50)

Why does the fish use the formal "Uds." when speaking to the children? The fish is portrayed as the children's guardian, a wiser figure, who is trying to protect them from the Cat. The fish also lives in the house with the children, so it is not a stranger, but somebody they are familiar with. "Ustedes" conveys distance and is usually used to show respect with older people, authority figures, or strangers. There are slight variations in countries where Spanish is the native language; for example, in Colombia "Usted" is used more commonly between friends or people you are meeting for the first time. The fish should use pronouns such as "tu" and "su":

22 Sugeng Hariyanto, "Methods in Translating Poetry," (Translation Directory.com, 2007). <http:// www.translationdirectory.com/article638.htm>; retrieved 17 Oct. 2007. 
“¡Muévanse! ¡Rápido! —dijo el pez—. Me están escuchando?

¡Porque están jugando!

¡Casi llega su mamá! Ella no tardará.

"Sound and meaning are one thing in any language." ${ }^{23}$ In the case of The Cat in the Hat, phonemic translation is of extreme importance. The Spanish translation should do more than just convey the meaning of the words in the source text; that new version must conserve its fun and excitement.

\section{Concluding Remarks}

This article has attempted to show that $\mathrm{L} 2$ translation is no longer the "Cinderella of translating among translators," 24 but rather a viable method that is not only advantageous in at least three distinct manners, and equally comparable to $\mathrm{Ll}$ translation in producing an ample if not superior translation. The Cat in the Hat provided a way to illustrate our main points because it had already been translated into Spanish, but it required improvement. Pokorn has come to similar conclusions in other types of texts ${ }^{25}$ :

The quality of translation, its fluency, and acceptability in the TL environment depend primarily on the yet undetermined individual abilities of the particular translator, his/her strategy and knowledge of the source and target cultures, and not his/ her mother tongue or the direction in which s/he is translating.

Shi Aiwei, Ch. 6.3.

María M. de la Cruz Traidor, "Traducción inversa: una realidad," TRANS 2004, <http:// www.trans.uma.es/Trans_8/t8_53-60_MDeLaCruz.pdf>; retrieved 19 Oct. 2007.

25

Nike K. Pokorn. Challenging the Traditional Axioms: Translation into a Non-Mother Tongue (Amsterdam: John Benjamins, 2005) 120. 
This remark leads to an entirely new set of questions and studies on this topic, but the purpose of this article is to clarify the misconceptions about translation directionality and to encourage more research and methodical application of linguistic theory in the field of translation directionality. The translator should think critically about the skills needed to produce a quality translation, as well as the variables that affect the end result. The mantra of 'impossibility of L2 translation' must be laid aside to foster skills and abilities that will cultivate translation of higher caliber.

It requires educators and business leaders to discard the negative value judgments that $\mathrm{L} 2$ translation has been given in the past. Let us not forget, as Campbell so clearly illustrated above, that L2 translation is an ability that can be improved. For novice translators there must be techniques established to overcome the initial shortcomings that this method might produce, until they are able to translate with maximum effectiveness. Other translators suggest team translating, or having the TT edited by a TL native speaker. The question of directionality in translation should not transform the translator into a "super translator" but allow translators to be made aware of their limitations, and continue to work towards strengthening their weaknesses. 